\title{
Lung Typical Carcinoid Tumor
}

National Cancer Institute

\section{Source}

National Cancer Institute. Lung Typical Carcinoid T umor. NCI Thesaurus. Code C45550.

A carcinoid tumor of the lung characterized by the absence of necrosis and the presence of less than 2 mitoses per 10 high power fields. 